\title{
Research on Disruptive Technology Recognition of China's Electronic Information and Communication Industry Based on Patent Influence
}

\author{
Weifeng Jia, Xi'an University of Posts and Telecommunications, China \\ Yongping Xie, Xidian University, China \\ Yanan Zhao, Xidian University, China \\ Ke Yao, Xi'an University of Posts and Telecommunications, China \\ Hui Shi, Computer Information Systems Department, California State Polytechnic University, USA \\ Dazhi Chong, School of Management, California Lutheran University, USA
}

\begin{abstract}
This paper adopts the knowledge map method and selects the field of mobile communication technology and wireless communication technology to represent the electronic information and communication industry for disruptive technology recognition. Through the analysis of keyword cooccurrence network and keyword frequency changes in the relevant literature of CNKI from January 2000 to April 2018 by CiteSpace software, this paper constructs a disruptive technology identification framework for China's electronic information and communications industry from the perspective of technological frontier and technological breakthrough. Using DeWinter Patent Database as the patent data source, this paper further verifies $5 \mathrm{G}$ technology and internet of things (IoT) technology from the perspective of patent impact. Finally, the roadmap of disruptive technology development in China's electronic information and communication industry is proposed to provide reference for the followup research of China's electronic information and communication industry's disruptive technology.
\end{abstract}

\section{KEYWORDS}

Communication Technology, Disruptive Technology, Knowledge Map, Patent Impact Factor, Technology Identification

\section{INTRODUCTION}

The term of disruptive technology was first introduced by Christensen in his research on the disk-drive industry (Christensen, 1997). A technology is considered disruptive when its utilization generates products with different performance attributes that may not have been valued by existing customers (Bower and Christensen, 1996). The idea disruptive technology was populated in 1990s and led to extensive discussion in both academic and industrial research (Boccardi, et.al., 2014; Kostoff, Boylan and Simons, 2004; Walsh, 2004). Disruptive technology is an innovation that significantly changes the way that consumers or businesses operate. However, many disruptive technologies are not totally new principles or new concepts, but rather the transfer of existing technologies from one domain to another, 
or the intersection of multiple existing technologies. Past research shows that disruptive technology can lead to the destruction of an old technology, a business model or a community (Walsh, 2004). From the point of view of technology path, disruptive technology breaks the old technology life cycle and form a new technology track. Therefore, for technology forecasters or technology roadmap planners, traditional technology prediction method (especially for sustaining technology) is not suitable for disruptive technology identification. There are many definitions of disruptive technologies that focus on different factors: industry wide product technology factors (Abernathy and Clark, 1985), the gap between substitutable technological learning curves on cost or performance basis (McKee, 1992).

This paper proposes a hybrid method combining both subjective and objective identification methods. We design a framework for disruptive technology identification. The framework includes three parts: part 1 is to identify frontier and breakthrough technologies in a specific industry; part 2 is to analyze the technical influence of frontier and breakthrough technologies determined in part 1 ; and part 3 is to identify disruptive technologies based on technology discontinuity analysis and technology application analysis. The proposed framework is applied in ICT Industry to identify disruptive technologies and verify the effectiveness. In the end, the potential disruptive technologies of mobile communication field and wireless communication field are obtained, and the road map of disruptive technology innovation and development is drawn from the evolution track of the identified disruptive technologies.

\section{LITERATURE REVIEW}

In the recent research, the identification of disruptive technology is mainly based on subjective identification method (technology management and technology application evaluation analysis) and objective observation method (scientific literature analysis and patent data analysis).

\subsection{Subjective Identification Method}

Vojak et al (2004) present a heuristic five-component methodology based on observing past changes in industries to identify potential disruptive technologies. Prediction of disruption is difficult and sometimes uncertain. Traditional road map methods are more suitable for sustaining technology other than disruptive technologies. Therefore, in order to improve analyzing the potential disruptive technologies in specific fields, many scholars have proposed to combine the traditional road map methods and the subjective identification methods, and put forward the second generation technology roadmap method. Kostoff et al. (2004) propose a realistic method with support of text mining literature to identify disruptive technologies. The authors use text-mining to identify candidate technology alternatives, critical technology components of each technology alternative, and experts for each of these identified technology components. Then experts are brought together to identify the component technology characteristics and generate a roadmap for each technology alternative. TRIZ theory (Altshuller, 1999) can be used in disruptive technology forecasting. Base on TRIZ theory, Sun et al. (2008) use the law of technology evolution to determine mainstream evolutionary technologies, laggard evolutionary technologies and whether technologies are potential disruptive technologies.

Building and analyzing multi-index evaluation framework is also a common subjective identification method. Sainio et al. (2007) uses the characteristics of the disruptive technology to build the evaluation framework that includes: two middle variables, the technology's disruptiveness potential and its strategic importance to the firm. The framework is also used in a cross-case analysis. Hang et al. (2011) constructs a framework for evaluating disruptive technologies based on market positioning, technological breakthrough, and government policies. Four examples have been studied to verify the effectiveness of the framework. Diab et al. (2015) designs a forecasting framework to predict disruptive technologies. After identifying factors affecting product sales, including marketing budget, marketing channels, corporate net income, and technical performance breakthroughs, both mathematical models and judgmental method are used a four-step forecasting process. 


\subsection{Objective Identification Method}

In terms of objective identification, patent data have been widely used in the technical fields. Mining patent text information is helpful for enterprises to: 1) identify the potential disruptive technologies as early as possible; 2) keep tabs on the research and development trends of competitors; 3) adjust the research and development strategies in time. Bloodworth (2012) first detect attribute sets that are derived from the academic literature based on frequency after data collection. Then quantitative content analysis and qualitative content analysis are conducted to identify discriminative linguistic markers. The markers appear to have predictive capabilities and may allow business organizations to identify disruptive innovations. Guo et al. (2019) designs a multidimensional measurement framework to evaluate the disruptive innovations based on the identified multidimensionality of potential disruptiveness: technological features, marketplace dynamics and external environment. The authors conduct a survey and present the survey results according to the framework indicators. The effectiveness of the proposed framework is also verified by comparing results against the real developments of the innovations.

Patent data analysis is considered as an effective and objective way to identify potential innovation. Until 2017, Clarivate Analytics, had provided eight state of innovation reports. It is a global leader that analyzes global patent application activity and scientific literature publications to provide trusted innovation insights. In 2016, patent activity data were collected across 12 key industries, and over 2.6 million patents were published. Patent data, such as number of patents, patent citations, patent abstracts and patent data analysis has been widely used in past scientific literature on identifying disruptive innovations (Su et al., 2016; Momeni and Rost 2016; Momeni and Rost 2016) identifies disruptive technologies through patent-development paths, k-core analysis and topic modeling of patent abstracts. The authors use patent citations to identify the relationships between patents and how important they are. The proposed method has been applied in photovoltaic industry to verify its effectiveness.

\section{IDENTIFYING DISRUPTIVE TECHNOLOGIES}

\subsection{Overall Research Framework}

Scientific literature and patents are two data sources to identify potential disruptive technologies. In this paper, the identification of disruptive technologies relies on the identification of frontier technologies and breakthrough technologies. In this paper, frontier technologies refers to technologies that represent the development direction of a certain technical field. Frontier technologies usually get a great deal of attention in scientific literature and can be determine based on experts' professional knowledge. Breakthrough technologies refers to technologies that get a great deal of attention in scientific literature and have outstanding technical influence. Breakthrough technologies contain technical performance attributes that have been excluded by the mainstream technologies. Bloodworth (2012) explores attribute sets that are derived from the academic literature based on frequency and predict the innovative technologies after content analysis. The author shows that the attribute sets of breakthrough technologies can be used to identify disruptive technologies. Past research have proposed systematic approaches (Lin et al 2012; Wang et al 2020; Wang, Li, Jones 2014; Xu 2000) to identify disruptive technologies, taking advantage of discovering frontier technologies from scientific literature (Kostoff, Boylan and Simons 2004; Cozzens et. al. 2010; Bloodworth 2012; Sood 2011).

Patent data information can be used as data source to identify potential disruptive technologies. (Su et al. 2016). Clarivate Analytics, is a global leader in providing trusted insights to accelerate the pace of innovation. Their annual innovation report mainly analyzes global patent application activity and scientific literature publications to provide innovation information. Su et al. (2016) used patent data information as data source to identify the emergence of disruptive technology. They put forward the identification index "patent impact factor" to summarize the trajectory of the disruptive 


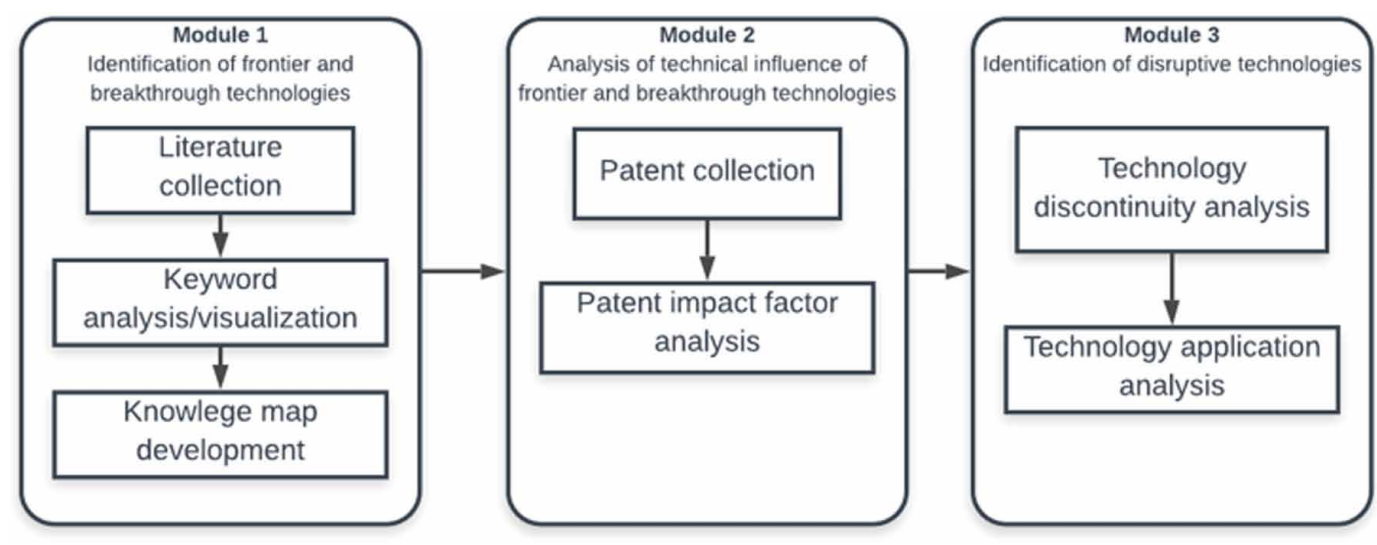

technology changes. The research confirms the effectiveness of using technical influence to identify the disruptive technology.

Given that scientific literature and patents have been widely used in identifying potential disruptive technologies, we propose a new framework for disruptive Technology Identification, as shown in Figure 1. There are three modules in the framework. Module 1 is designed to identify frontier and breakthrough technologies through keyword analysis and knowledge map development. In this module, first, collect literature in related areas. Second, determine keyword (key technologies) list; Third, use knowledge map tool to visualize and analyze knowledge networks and identify frontier and breakthrough technologies. Module 2 is designed to analyze technical influence of frontier and breakthrough technologies. In this module, first collect patents in related areas. Second, use patent impact factor to analyze the technical influence of frontier and breakthrough technologies. Module 3 is designed to identify potential disruptive technologies. In this module, use technology discontinuity analysis and technology application analysis to identify disruptive technologies. Detailed steps are presented in the following sections.

\subsection{Detailed Analysis Steps}

\subsubsection{Knowledge Map and keyword Analysis}

Scientific literature in related fields is the data source for module 1. Knowledge map and keyword analysis are two essential steps in the first module as well. Knowledge map is a visual representation of knowledge that facilities further analysis of knowledge. Visualization, such as, keywords co-occurrence network, word frequency change are effective ways of representation of knowledge (Matsuo and Ishizuka 2004; Su and Lee 2010). There are many cases where knowledge map analysis has been utilized. Callon et al. (1986) proposed science and technology dynamic map. By counting the number of occurrences of word pair in the paper within the same category, the relationship between papers is measured by the number of co-occurrences. And then the closeness between papers is determined to further analyze the subject. Su et al (2010) utilizes "Keyword Co-occurrence" for visualizing knowledge structure created by journal papers. In their research, the proposed method shows a way of finding potential applications by visualizing and evaluating knowledge structure. Chen (2006) developed a Java application named CiteSpace, it is a knowledge map analysis tool on for knowledge domain visualization and trend analysis in scientific literature. CiteSpace focuses on identifying the fast-growth topical areas, finding citation hotspots by analyzing collaboration networks, author cocitation networks, and document co-citation networks. 
In this paper, we propose to use key technologies as keywords as input for knowledge map analysis. We design a systematic way to create and extract keywords from scientific publications and current research trends. Key technologies are inputs for knowledge map analysis. The knowledge map analysis includes visualization and analysis of "Research hotspot network", "Key technology co-occurrence network", and "Word frequency change network" against scientific publications.

\subsubsection{Patent Impact Factor Analysis}

Su et al. (2016) put forward the identification index "patent impact factor" to summarize the trajectory of the disruptive technology changes. "Patent impact factor" refers to the ratio of the total number of citations of a patented technology in the year of publication and two years thereafter to the number of patents in that year. The identification of disruptive technologies is based on the identification of frontier technologies and breakthrough technologies. This paper utilizes "Patent impact factor" to measure the technical influence of the identified frontier and breakthrough technologies, and further identify the disruptive technologies of specified areas.

A single patent indicator cannot determine whether a technology is a disruptive technology. Three indicators including patent count, patent citation count and patent citation rate can clearly show the difference between disruptive technology and sustaining technology in the development path, but based on our best knowledge, we do not have access to collect all three indicators promptly. Therefore, we adopt "Patent impact factor" as a tool to evaluate the potential disruptive technologies, given that "Patent impact factor" is more time sensitive.

\section{A CASE STUDY BASED ON SCIENTIFIC LITERATURE AND PATENTS}

In this paper, we present the process of identifying disruptive technologies via a case study focused on ICT. In recent years, ICT have played an important role in the development of global economic growth (Cao et al 2019; Carter et al 2020; Gorkhali et al 2019; Li 2018; Sui and Liu 2020; Xu et al 2016). The innovation in ICT has a positive impact on economy and society (Xu et al 2018; Wu et al 2014). Technological innovation affects all aspects of our world, from business to transportation to how we communicate with each other (Xu 2014; Zhang 2019). For enterprises, communication technology can facilitate collecting market statistics and making timely decisions by directors or managers, reduce the cost and increase the revenue of businesses. At the same time, the development of ICT improves the efficiency of information sharing and promotes the effective use of resources (Xu 2016; Xu and Viriyasitavat 2019). More importantly, the innovation in ICT promotes the global communication and exchange. We will provide details of the case study in the following sections.

\subsection{Extracting Key Technologies}

The initial step is to extract key ICT. The extraction includes collection and classification. The communication technology in ICT is divided into five technical fields: fixed communication, mobile communication, satellite communication, microwave communication, and wireless communication. Since the development of new generation information technology focus on the development of mobile communication and wireless communication, and both fields has attracted the research community's attention, this case study focuses on key technologies in the field of mobile communication and wireless communication, as listed in Table 1.

The disruptive technologies of the ICT are identified utilizing the importance of technology application and technology discontinuity. A technological discontinuity might be defined as "innovations that dramatically advance an industry's price vs. performance frontier". Technological discontinuities can trigger a period of incremental technical change (Anderson and Tushman 1990). Technology discontinuity is a technology reform and the most important index for identifying disruptive technologies. 
Table 1. Key technologies in mobile communication and wireless communication

\begin{tabular}{|c|l|}
\hline category & \multicolumn{1}{c|}{ key technology } \\
\hline $\begin{array}{c}\text { Mobile } \\
\text { communication }\end{array}$ & $\begin{array}{l}\text { 5G technology (Xu, He and Li 2014; Li, Xu and Zhao 2018), 4G technology, Orthogonal } \\
\text { frequency division multiplexing technology, Software Defined Radio technology, Smart } \\
\text { antenna technology, multi-input-multioutput technology, Core Network Technology based } \\
\text { on IP, Multi-user Detection Technology 3G, cdma technology, wcdma technology, tdma } \\
\text { technology, scdma technology, Fusion Technology of WiFi and LET, Cognitive radio } \\
\text { technology, Multi-antenna technology, cooperative communication technology, Dense } \\
\text { networking technology, heterogeneous network fusion technology, Mobile Network Security } \\
\text { Technology, Natural language interaction, Hybrid reality technology, Robot process } \\
\text { automation, Artificial intelligence technology (Lu 2019), Open source technology }\end{array}$ \\
\hline $\begin{array}{c}\text { Wireless } \\
\text { communication }\end{array}$ & $\begin{array}{l}\text { CDMA2000, Infrared(IR), Radio frequency identification technology (Lai et al 2017; Li, Xu } \\
\text { and Zhao 2015), UMTS/3GPPw/HSDPA, WiMAXWi-Fi, NMA, New coding Modulation and } \\
\text { Link Adaptive Technology, Massive MIMO, High frequency communication, wireless return } \\
\text { technology, virtualization technology, UWB base station UBR technology, fat base station } \\
\text { technology, NFV/SDN technology, ultra-wideband (UWB) technology, space-time processing } \\
\text { technology, improvised network technology, Internet of Things technology (Li, Li, Zhao 2014; } \\
\text { Qi et al 2017; Whitmore et al 2015), shared spectrum technology, wireless sensor network } \\
\text { technology, Vehicle networking, cognitive radio, Bluetooth technology, zigbee technology, } \\
\text { smart grid technology, cdma technology }\end{array}$ \\
\hline
\end{tabular}

The development of a technology goes through S-type development cycle including initial period, growth period, and maturity period (Schilling and Esmundo 2009). When the technology development enters the maturity stage, the slope of the technology development curve becomes flatter, indicating that the development of the technology becomes slower. At this point, technology progress will be achieved through another "technology discontinuity". The discontinuous technology progress of an existing technology will be obtained by changing the original technology development trajectory. It breaks through the life cycle of the original technology, and creates a new technology orbit, which is also an important feature of disruptive technology (Adner 2002).

This paper analyzes important areas of electronics and information technogies, and classifies key technologies in the ICT into three categories (Xu and Liang, 2016), as shown in Table 2.

\subsection{Identification of Frontier and Breakthrough Technologies}

\subsubsection{Data Collection}

In this paper, we choose the full-text database of Chinese academic journals (CNKI) as the data source of the literature. The time retrieval span is from January 2000 to April 2018. The keywords we use in the search term option are the five categories of electronic information and communication technology: fixed communication technology, mobile communication technology, satellite communication technology, wireless communication technology and microwave communication technology. In order to retrieve the most related academic scientific papers in electronic information and communication technology, to ensure the credibility of the research results, unrelated papers, non-research documents, such as solicitation notices, rules and regulations, news briefs are removed.

As we discussed in section 4.1, this case study only utilizes key technologies in the field of mobile communication and wireless communication to identify potential disruptive technologies. Therefore, after looking through various technical fields of ICT industry, we keep the related scientific papers of mobile communication technology and wireless communication technology.

\subsubsection{Knowledge Map Analysis}

1. Mobile Communications Technology Dataset 
Table 2. Classification of electronic information and communication technologies

\begin{tabular}{|c|c|}
\hline Technology category & Classification index \\
\hline \multirow{2}{*}{ Important technology } & Technology core index \\
\cline { 2 - 2 } & Technology zonality index \\
\cline { 2 - 2 } & Technology application importance index \\
\hline \multirow{2}{*}{ Common technology } & Technology versatility index \\
\cline { 2 - 2 } & Technology application importance index \\
\hline \multirow{2}{*}{ Disruptive technology } & Technology discontinuity index \\
\cline { 2 - 2 } & Technology application importance index \\
\hline
\end{tabular}

The scientific literature related to mobile communication technology have been collected from CNKI. The publication time span is from 2000 to 2018. "Mobile communication technology" is used as the subject. A total of 4272 papers are retrieved after the accurate matching. The key words of 1971 articles on mobile communication technology are analyzed as nodes by CiteSpace. The keyword co-occurrence analysis result is presented in Figure 2 (threshold $=$ top 30).

In the keyword co-occurrence network, the red circle in the graph indicates frontier technology that attracts more attention. Based on the analysis result shown in Figure 2, 5G technology is one of the hot topics in mobile communication technology. Figure 3 shows the keyword frequency change network diagram in mobile communication technology.

\section{Wireless Communications Technology Dataset}

The scientific literature related to wireless communication technology have been collected from CNKI. The publication time span is from 2000 to 2018. "Mobile communication technology" is used as the subject. A total of 1400 papers are kept after the accurate matching and filtering. The keywords on wireless communication technology are analyzed as nodes by CiteSpace. The keyword co-occurrence analysis result is presented in Figure 3 (threshold $=$ top 30). Figure 5 shows the keyword frequency change network diagram in mobile communication technology, from which we can see the evolution of key technologies in wireless communication technology field.

\subsubsection{Keyword Analysis}

Through the keyword analysis of the collected literature, the CiteSpace information visualization software provides the keyword frequency, the centrality and the burst value of a certain technology. The frequency of key technology represents the popularity of this technology. The centrality in this paper measures the percentage of the number of shortest paths in a keyword co-occurrence network to which a given node (keyword) belongs. The node with high centrality acts as a bridge between various technologies in the network and plays the role of technology interconnection. The centrality can help us to identify frontier technologies and disruptive technologies. The burst value is obtained by examining the change of words frequency over time.

The bursts of keywords can be used to determine sharp increases of interest in an area. Burst detection can identify emergent terms that are called burst terms. With number of occurrences of keywords, the emerging research fronts can be determined (Shibata et al, 2011).

\section{Frontier Technology Identification}




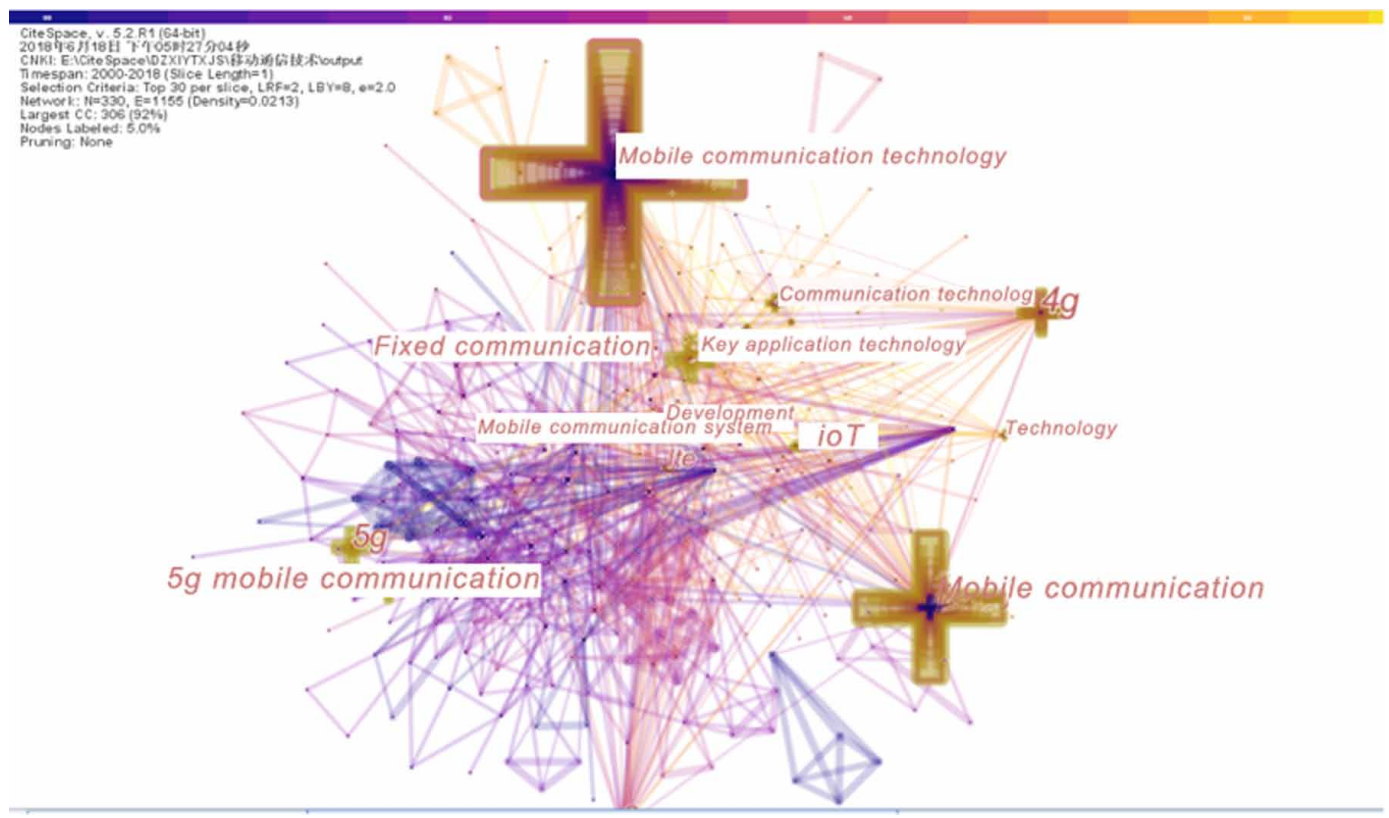

Figure 3. Keyword frequency change network diagram for mobile communication technology

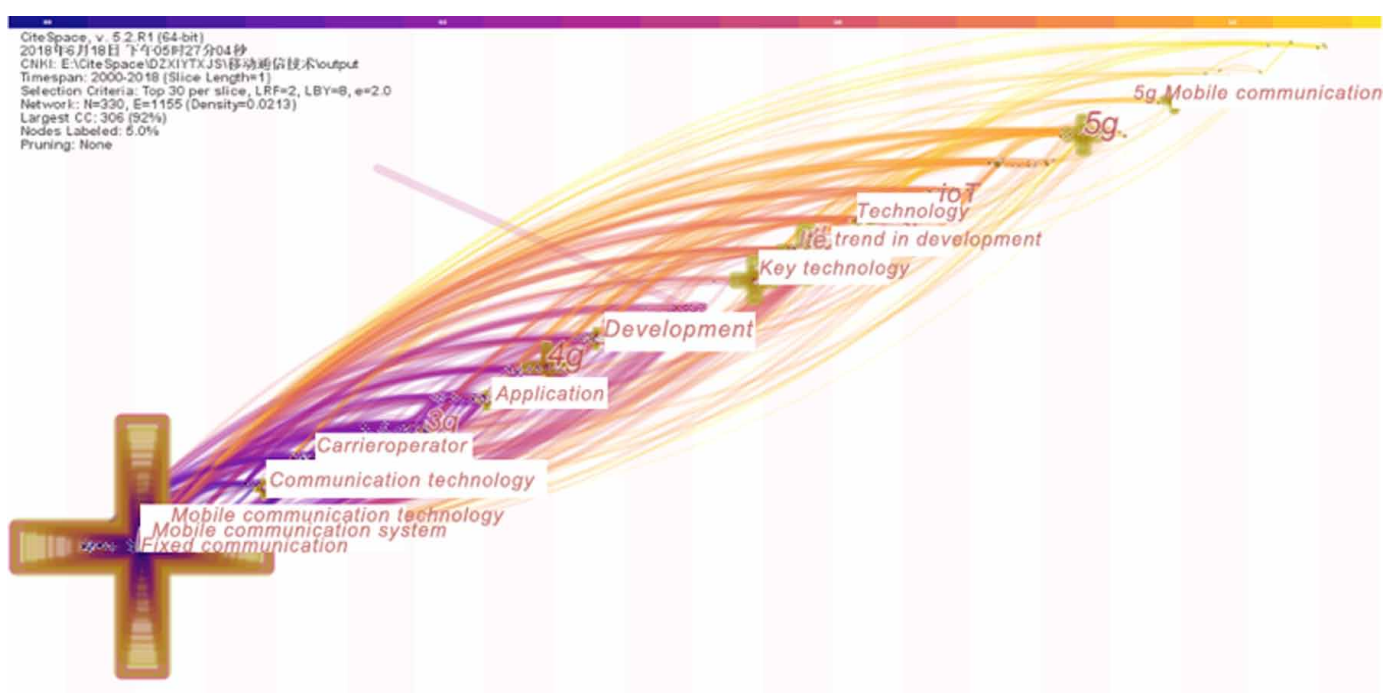

In Table 2, top 10 mobile communication technologies are listed according to their bursts, which represents the frontier technology in the mobile communication industry. 5G technology has the highest burst value 6.4 . 


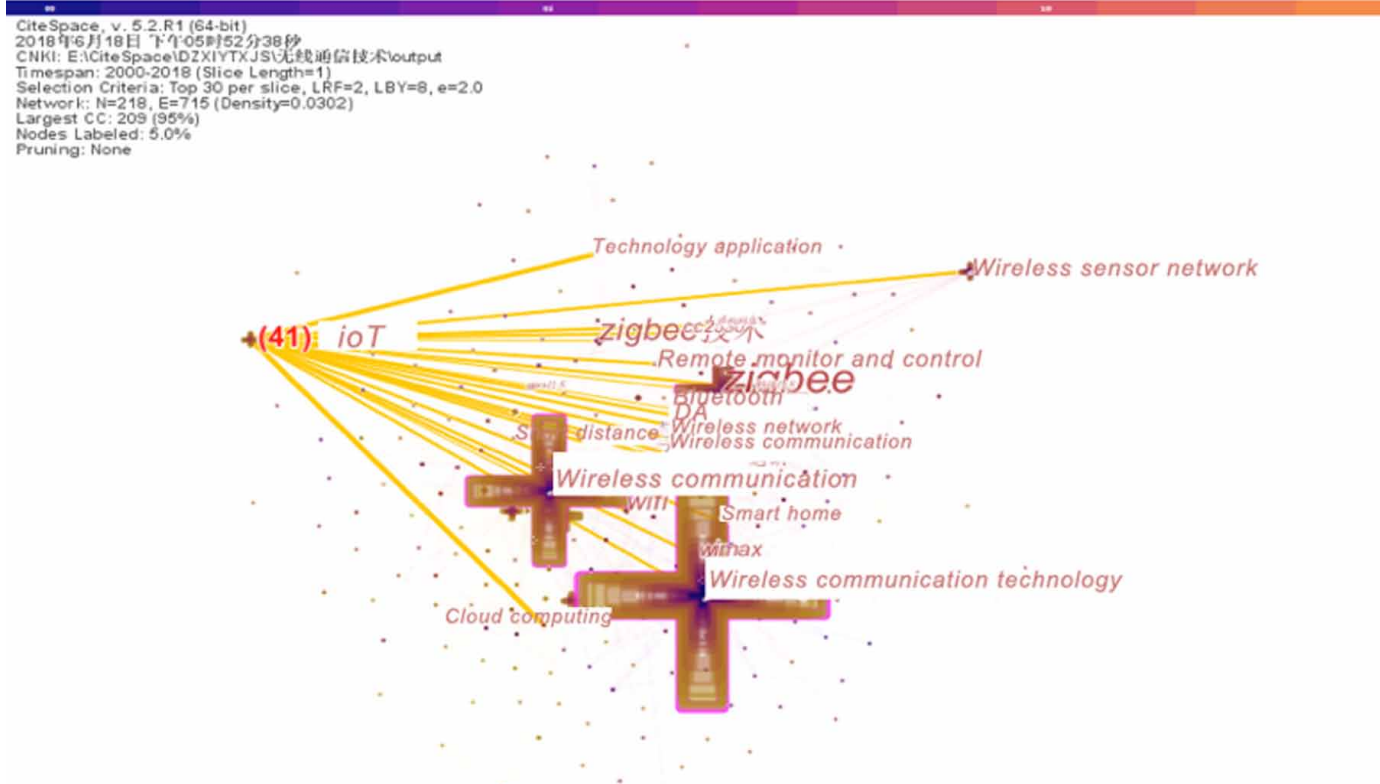

Figure 5. Keyword frequency change network diagram for wireless communication technology

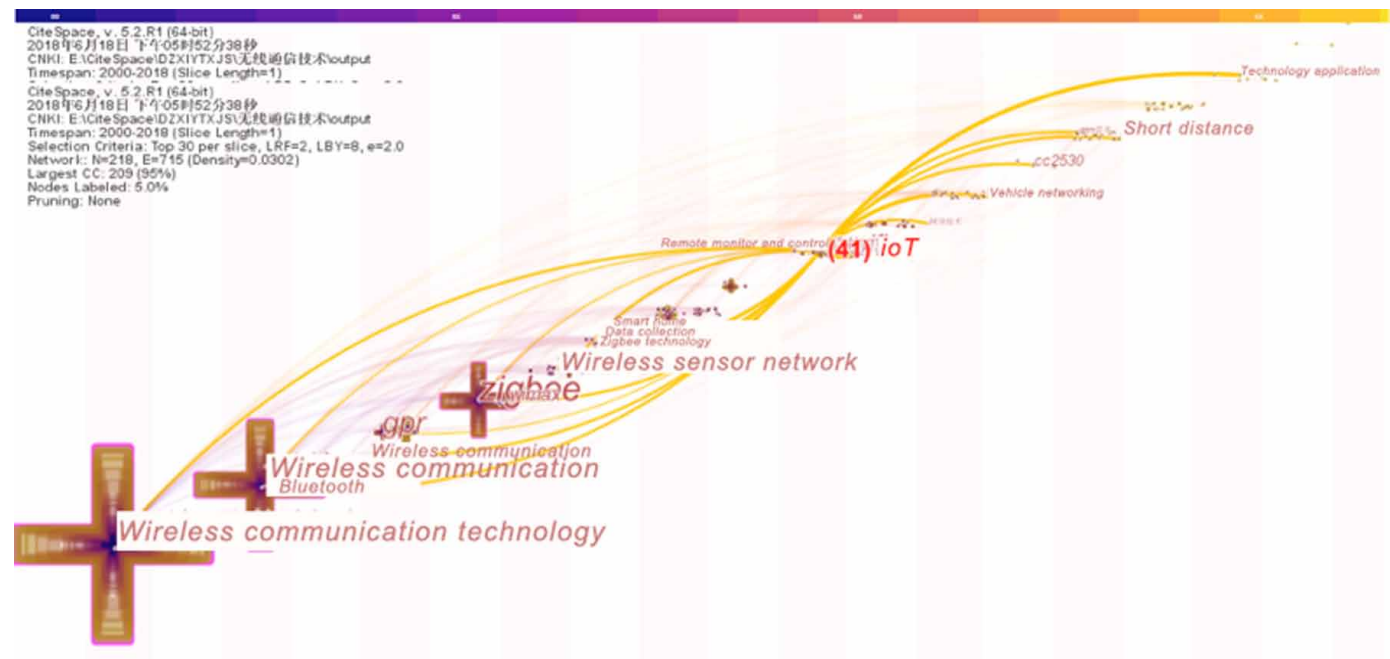

In Table 3, the top 10 wireless communication technologies are listed according to their bust value. The Internet of Things technology, whose burst value reaches 6.2, is a frontier technology in the field of wireless communication, 
Table 2. Frontier technologies for mobile communications

\begin{tabular}{|c|c|c|}
\hline Technical name & Burst & Centrality \\
\hline 5G & 6.4 & 0.2 \\
\hline Large-scale mimo & 3.8 & 0.16 \\
\hline $\begin{array}{c}\text { Orthogonal frequency multiplexing } \\
\text { technique }\end{array}$ & 3.2 & 0.3 \\
\hline D2D technology & 3 & 0.02 \\
\hline Full duplex technology & 2.8 & 0.02 \\
\hline Virtual reality technology & 2.6 & 0 \\
\hline Smart antenna & 2.4 & 0.16 \\
\hline $4 \mathrm{G}$ & 1.2 & 0.33 \\
\hline scdma & 1 & 0.2 \\
\hline wcdma & 1 & 0.18 \\
\hline
\end{tabular}

\section{Breakthrough Technology Identification}

As shown in Table 4, the mobile communication technologies have high frequency and burst value in the co-occurrence network. The combination of high frequency and burst value can measure the technical breakthrough index to explain the disruptive potential. It can be concluded from Figure 2 and Table 4 that $5 \mathrm{G}$ is the most representative breakthrough technology. After exploring $5 \mathrm{G}$ related technology applications, we conclude that $5 \mathrm{G}$ technology will bring disruptive innovation to mobile phone terminal at least in three aspects: mobile phone display screen, mobile phone battery, and operating system, which implements breakthrough technologies for mobile communications.

As shown in Table 5, the wireless communication technologies have high frequency and burst value in the co-occurrence network. The combination of high frequency and burst value can measure the technical breakthrough index to explain the disruptive potential. It can be concluded from Figure 4 and Table 5 that Internet of Things is the most representative breakthrough technology. Artificial

Table 3. Frontier technologies for wireless communications

\begin{tabular}{|c|c|c|}
\hline Technology name & Burst & Centrality \\
\hline IoT & 6.2 & 0.03 \\
\hline Zigbee technology & 3.2 & 0.06 \\
\hline Ultra-wideband technology & 2.8 & 0.03 \\
\hline Shared spectrum technology & 2.4 & 0 \\
\hline $\begin{array}{c}\text { Multiple Antenna Technology } \\
\text { (Massive MIMO) }\end{array}$ & 2 & 0.01 \\
\hline bluetooth technology & 1.8 & 0.02 \\
\hline Smart grid & 1.2 & 0 \\
\hline Vehicle networking technology & 1.2 & 0.03 \\
\hline Smart home & 1.1 & 0 \\
\hline Cognitive radio & 1 & 0 \\
\hline
\end{tabular}


Table 4. Breakthrough technologies for mobile communications

\begin{tabular}{|c|c|c|}
\hline frequency & Burst & Technical name \\
\hline 121 & 0 & $3 \mathrm{G}$ \\
\hline 87 & 6.4 & $5 \mathrm{G}$ \\
\hline 57 & 1.2 & $4 \mathrm{G}$ \\
\hline 24 & 3.2 & $\begin{array}{c}\text { Orthogonal frequency multiplexing } \\
\text { technique }\end{array}$ \\
\hline 21 & 2 & ofdm \\
\hline 20 & 1 & scdma \\
\hline 16 & 1 & wcdma \\
\hline 7 & 3.8 & Large-scale mimo \\
\hline 4 & 2.4 & Smart antenna \\
\hline 4 & 0 & tdma \\
\hline
\end{tabular}

Intelligence technologies provide the framework and tools to analytics of real time monitoring and automation use cases for Internet of Things. Concepts from artificial intelligence can be applied to specific Internet of Things use cases to facilitate decision-making. With combination of Internet of Things and artificial intelligence, the physical world can be represented in a consistent virtual environment, which brings breakthrough of wireless communication technologies. The disruptive status of the Internet of Things has been strengthened.

\subsection{Technical Influence of Frontier and Breakthrough Technologies}

Since frontier technologies and breakthrough technologies are used to identify disruptive technologies, the technical influence of the identified technologies with disruptive potential is measured based on "patent impact factor". The Derwent Innovation Index (DII) is used as the data source of technical patents in related fields. The identified frontier technologies and breakthrough technologies are used as the subjects of searching. Disruptive technologies can be identified after we determine the technical influence of frontier technologies and breakthrough technologies.

Table 5. Breakthrough Technologies for Wireless Communication

\begin{tabular}{|c|c|c|}
\hline frequency & Burst & Technology name \\
\hline 161 & 0 & Wireless sensor network technology \\
\hline 123 & 6.2 & Internet of Things technology \\
\hline 101 & 3.2 & Zigbee technology \\
\hline 46 & 1.1 & Smart home \\
\hline 32 & 2.8 & Ultra-wideband technology \\
\hline 28 & 1.2 & cdmart grid \\
\hline 24 & 0 & bluetooth \\
\hline 18 & 1.8 & Vehicle networking technology \\
\hline 6 & 1.2 & Cognitive radio \\
\hline 4 & 1 & \\
\hline
\end{tabular}




\section{Mobile Communications Technology}

In this paper, 7333 patent documents were retrieved by using $\mathrm{TS}=(5 \mathrm{G})$ and 2379 patent documents were retrieved by using $\mathrm{TS}=(3 \mathrm{G})$. As shown in Figure 6, 5G related patents appear later, while $5 \mathrm{G}$ technologies have a higher citation rate in the early stages. High data capacity and data transfer rate of $5 \mathrm{G}$ mobile communication technology requires support of more spectrum resources. The emergence of 5G mobile communication technology has significant improvement in coverage performance, system security, transmission delay, user experience and so on compared with 4G mobile communication technology. Therefore, $5 \mathrm{G}$ technology has been considered to be a disruptive technology immediately as it appears.

\section{Wireless Communications Technology}

For wireless communications technology, 5846 patent documents were retrieved by using $\mathrm{TS}=$ (IoT) and 7586 patent documents were retrieved by using $\mathrm{TS}=$ (wireless sensor network). As shown in Figure 7, the citation rate of patents on Internet of Things technology reached its peak around 2016. Internet of Things technology was gradually recognized as frontier technology and breakthrough technology (Cai et al 2014; Fan et al 2014; Fang et al 2014; Jiang et al 2014; Li et al 2014; Priyanka et al 2020; Viriyasitavat et al 2019; Xiao et al 2014; Xu, Xu, Cai et al 2014; Yang et al 2018; Yin et al 2020; Zheng et al 2014). As the patent citation rate of Internet of Things is increasing year by year, the technical influence is becoming more and more apparent, which shows the development of a disruptive technology.

\section{ROAD MAP FOR DISRUPTIVE TECHNOLOGY DEVELOPMENT IN THE ICT INDUSTRY}

In this paper, we use the basic characteristics of disruptive technology, the proposed framework for disruptive technology identification, relevant literature and patent data in the field of mobile communication and wireless communication technology to analyze and identify the frontier technologies and breakthrough technologies, and further identify the potential disruptive technology. (Kostoff, Boylan, Simons 2004).

To our best knowledge, disruptive technologies themselves are proposed in the context of business innovation. Disruptive technologies generally start from low-end. They are characterized by simplicity, convenience, and cheapness at the initial stage. With the continuous improvement of performance and functions, a new technology track is formed to replace existing technologies and

Figure 6. Key technologies of mobile communications and 5G technology citation rate

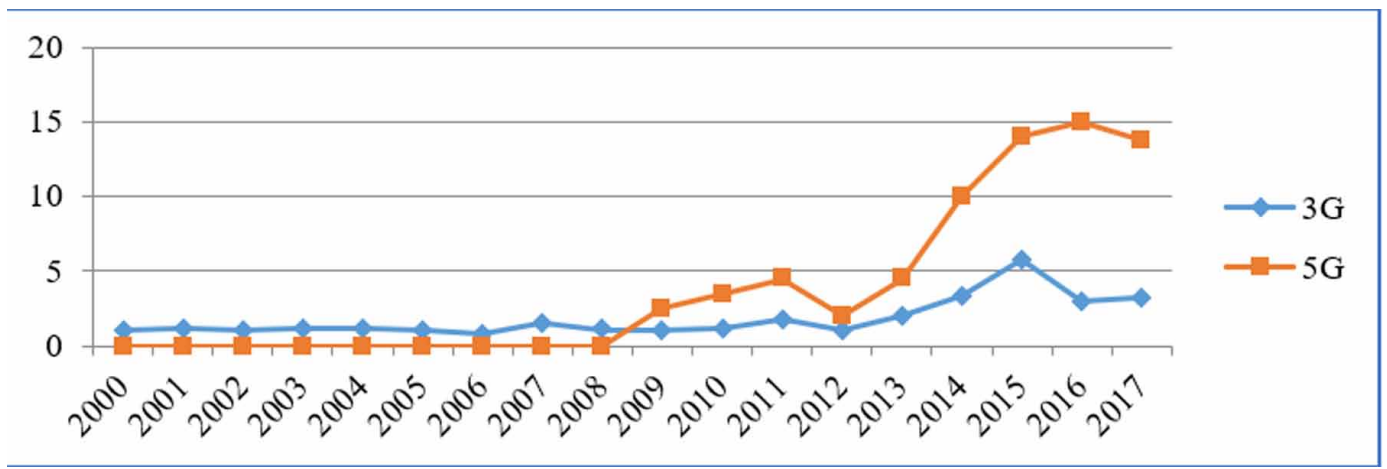


Figure 7. Three-year citation rate of wireless communication key technology and Internet of Things technology

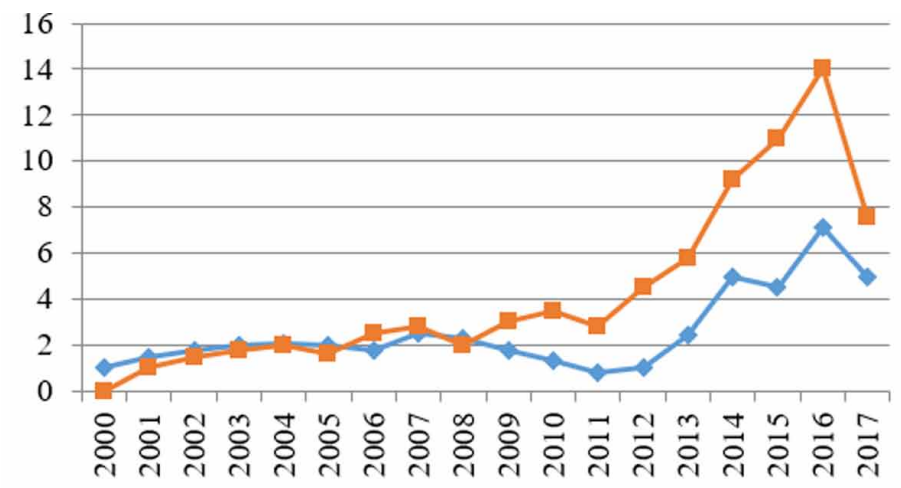

$\rightarrow$ Wireless communication key technology

- - Internet of things technology

open new markets. We can set performance goals based on user demands to develop technology development strategies, change enterprise performance measurement from the perspective of new technology competitiveness, help enterprises timely adjust technology innovation strategies, avoid risks, improve economic benefits and reduce costs. To conclude, the road map of disruptive technology development is presented as shown in Figure 8.

\section{CONTRIBUTIONS AND IMPLICATIONS}

In this paper, we propose a new framework for disruptive technology identification. This framework includes three modules to: 1) identify frontier and breakthrough technologies through keyword analysis and knowledge map development;2) analyze technical influence of frontier and breakthrough technologies; 3) identify potential disruptive technologies. We apply the proposed framework in a case study focused on ICT. In the case study, first, literature and key technologies are collected in both mobile communication and wireless communication; second, knowledge map visualization is adopted to create keyword co-occurrence network diagram; third, frontier and breakthrough technologies are identified and analyzed by using patent impact factor. In the case study, 5G technology and Internet of Things technology are identified as frontier and breakthrough technologies. Then 5G technology and Internet of Things technology are identified and verified as potential disruptive technologies by analyzing patent impact and comparing with traditional key technologies. At the end of this paper, a road map for disruptive technology development is proposed to provide reference for the follow-up research of ICT disruptive technology.

Future studies include: 1) conducting the disruptive technologies identification through different research directions in the fields of electronic information and communications technology; 2)

Figure 8. Road map for disruptive technology development

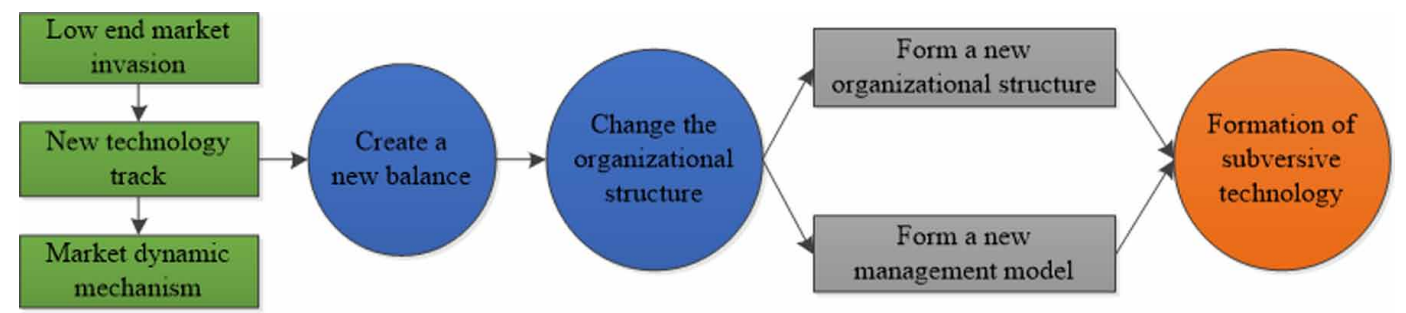


collecting more related scientific literature and patent data; 3 ) improving the dataset quality by using more search options.

\section{ACKNOWLEDGMENT}

This paper is supported by National Natural Science Foundation of China (NSFC: 71804147, 71472144, 71672143,71972153,71502090), Humanities and Social Sciences General Project of the Ministry of Education of China(20YJA790033), the Soft Science Research Project of Shanxi Province (2018KRM040,2019KRM006). 


\section{REFERENCES}

Abernathy, W. J., \& Clark, K. B. (1985). Innovation: Mapping the winds of creative destruction. Research Policy, 14(1), 3-22. doi:10.1016/0048-7333(85)90021-6

Adner, R. (2002). When are technologies disruptive? A demand-based view of the emergence of competition. Strategic Management Journal, 23(8), 667-688. doi:10.1002/smj.246

Al'tshuller, G. S. (1999). The innovation algorithm: TRIZ, systematic innovation and technical creativity. Technical Innovation Center, Inc.

Anderson, P., \& Tushman, M. L. (1990). Technological discontinuities and dominant designs: A cyclical model of technological change. Administrative Science Quarterly, 35(4), 604-633. doi:10.2307/2393511

Bloodworth, I. (2012). A Search for Discriminative Linguistic Markers in ICT Practitioner Discourse, for the Ex Ante Identification of Disruptive Innovation. Victoria University of Wellington.

Boccardi, F., Heath, R. W., Lozano, A., Marzetta, T. L., \& Popovski, P. (2014). Five disruptive technology directions for 5G. IEEE Communications Magazine, 52(2), 74-80. doi:10.1109/MCOM.2014.6736746

Bower, J. L., \& Christensen, C. M. (1996). Disruptive technologies: Catching the wave. Journal of Product Innovation Management, 1(13), 75-76.

Cai, H., Xu, L., Xu, B., Xie, C., Qin, S., \& Jiang, L. (2014). IoT-based Configurable Information Service Platform for Product Lifecycle Management. IEEE Transactions on Industrial Informatics, 10(2), 1558-1567. doi:10.1109/TII.2014.2306391

Callon, M., Rip, A., \& Law, J. (Eds.). (1986). Mapping the dynamics of science and technology: Sociology of science in the real world. Springer. doi:10.1007/978-1-349-07408-2

Cao, X., Chaudhry, S., \& Xu, L. (2019). Electronic Markets in Emerging Markets. Electronic Markets, 29(2), 151-152. doi:10.1007/s12525-019-00343-0

Carter, E., Adam, P., Tsakis, D., Shaw, S., Watson, R., \& Ryan, P. (2020). Enhancing pedestrian mobility in Smart Cities using Big Data. Journal of Management Analytics. 10.1080/23270012.2020.1741039

Chen, C. (2006). CiteSpace II: Detecting and visualizing emerging trends and transient patterns in scientific literature. Journal of the American Society for Information Science and Technology, 57(3), 359-377. doi:10.1002/ asi. 20317

Cozzens, S., Gatchair, S., Kang, J., Kim, K. S., Lee, H. J., Ordóñez, G., \& Porter, A. (2010). Emerging technologies: Quantitative identification and measurement. Technology Analysis and Strategic Management, 22(3), 361-376. doi:10.1080/09537321003647396

Diab, S., Kanyaru, J., \& Zantout, H. (2015). Disruptive innovation: a dedicated forecasting framework. In Agent and Multi-Agent Systems: Technologies and Applications (pp. 227-237). Springer. doi:10.1007/978-3319-19728-9_19

Fan, Y., Yin, Y., Xu, L., Zeng, Y., \& Wu, F. (2014). IoT based Smart Rehabilitation System. IEEE Transactions on Industrial Informatics, 10(2), 1568-1577. doi:10.1109/TII.2014.2302583

Fang, S., Xu, L., Zhu, Y., Ahati, J., Pei, H., Yan, J., \& Liu, Z. (2014). An Integrated System for Regional Environmental Monitoring and Management Based on Internet of Things. IEEE Transactions on Industrial Informatics, 10(2), 1596-1605. doi:10.1109/TII.2014.2302638

Gorkhali, A., \& Xu, L. (2019). Enterprise Architecture, Enterprise Information Systems and Enterprise Integration: A Review Based on Systems Theory Perspective. Journal of Industrial Integration and Management, 4(2), 1950001. doi:10.1142/S2424862219500015

Guo, J., Pan, J., Guo, J., Gu, F., \& Kuusisto, J. (2019). Measurement framework for assessing disruptive innovations. Technological Forecasting and Social Change, 139, 250-265. doi:10.1016/j.techfore.2018.10.015

Hang, C. C., Chen, J., \& Yu, D. (2011). An Assessment Framework for Disruptive Innovation. IEEE Engineering Management Review, 41(5), 109-118. 
Jiang, L., Xu, L., Cai, H., Jiang, Z., Bu, F., \& Xu, B. (2014). An IoT Oriented Data Storage Framework in Cloud Computing Platform. IEEE Transactions on Industrial Informatics, 10(2), 1443-1451. doi:10.1109/ TII.2014.2306384

Kostoff, R. N., Boylan, R., \& Simons, G. R. (2004). Disruptive technology roadmaps. Technological Forecasting and Social Change, 71(1-2), 141-159. doi:10.1016/S0040-1625(03)00048-9

Lai, C., Jackson, P., \& Jiang, W. (2017). Shifting paradigm to service-dominant logic via Internet-of-Things with applications in the elevators industry. Journal of Management Analytics, 4(1), 35-54. doi:10.1080/2327 0012.2016.1259967

Li, L. (2018). China's manufacturing locus in 2025: With a comparison of "Made-in-China 2025" and "Industry 4.0". Technological Forecasting and Social Change, 135, 66-74. doi:10.1016/j.techfore.2017.05.028

Li, L., Li, S., \& Zhao, S. (2014). QoS-aware scheduling of services-oriented Internet of Things. IEEE Transactions on Industrial Informatics, 10(2), 1497-1505. doi:10.1109/TII.2014.2306782

Li, S., Oikonomou, G., Tryfonas, T., Chen, T., \& Xu, L. (2014). A Distributed Consensus Algorithm for Decision Making in Service-oriented Internet of Things. IEEE Transactions on Industrial Informatics, 10(2), 1461-1468. doi:10.1109/TII.2014.2306331

Li, S., Xu, L., \& Zhao, S. (2015). The Internet of Things: A Survey. Information Systems Frontiers, 17(2), 243-259. doi:10.1007/s10796-014-9492-7

Li, S., Xu, L., \& Zhao, S. (2018). 5G Internet of Things: A Survey. Journal of Industrial Information Integration, 10,1-9. doi:10.1016/j.jii.2018.01.005

Lin, Y., Duan, X., Zhao, C., \& Xu, L. (2012). Systems Science Methodological Approaches. CRC Press, Taylor \& Francis. doi:10.1201/b13095

Lu, Y. (2019). Artificial intelligence: A survey on evolution, models, applications and future trends. Journal of Management Analytics, 6(1), 1-29.

Matsuo, Y., \& Ishizuka, M. (2004). Keyword extraction from a single document using word co-occurrence statistical information. International Journal of Artificial Intelligence Tools, 13(1), 157-169.

McKee, D. (1992). An organizational learning approach to product innovation. Journal of Product Innovation Management: An International Publication of the Product Development \& Management Association, 9(3), 232-245. doi:10.1111/1540-5885.930232

Momeni, A., \& Rost, K. (2016). Identification and monitoring of possible disruptive technologies by patentdevelopment paths and topic modeling. Technological Forecasting and Social Change, 104, 16-29. doi:10.1016/j. techfore.2015.12.003

Priyanka, E., Maheswari, C., Thangavel, S., \& Ponni Bala, M. (2020). Integrating IoT with LQR-PID controller for online surveillance and control of flow and pressure in fluid transportation system. Journal of Industrial Information Integration, 17, 100127. doi:10.1016/j.jii.2020.100127

Qi, J., Yang, P., Min, G., Amft, O., Dong, F., \& Xu, L. (2017). Advanced Internet of Things for Personalized Healthcare Systems: A Survey. Pervasive and Mobile Computing, 41, 132-149. doi:10.1016/j.pmcj.2017.06.018

Sainio, L. M., \& Puumalainen, K. (2007). Evaluating technology disruptiveness in a strategic corporate context: A case study. Technological Forecasting and Social Change, 74(8), 1315-1333. doi:10.1016/j.techfore.2006.12.004

Schilling, M. A., \& Esmundo, M. (2009). Technology S-curves in renewable energy alternatives: Analysis and implications for industry and government. Energy Policy, 37(5), 1767-1781. doi:10.1016/j.enpol.2009.01.004

Shibata, N., Kajikawa, Y., Takeda, Y., Sakata, I., \& Matsushima, K. (2011). Detecting emerging research fronts in regenerative medicine by the citation network analysis of scientific publications. Technological Forecasting and Social Change, 78(2), 274-282. doi:10.1016/j.techfore.2010.07.006

Sood, A., \& Tellis, G. J. (2011). Demystifying disruption: A new model for understanding and predicting disruptive technologies. Marketing Science, 30(2), 339-354. doi:10.1287/mksc.1100.0617 
Su, H. N., \& Lee, P. C. (2010). Mapping knowledge structure by keyword co-occurrence: A first look at journal papers in Technology Foresight. Scientometrics, 85(1), 65-79. doi:10.1007/s11192-010-0259-8

Su, J., Liu, J., Wang, Z., Chen, Y., \& Jiang, Z. (2016). Evolution and early identification of disruptive Technology-A case study of smartphone. Science Research Management, 2016(3), 13-20.

Sui, J., \& Liu, Y. (2020). Co-Evolution of Technology and Institutions in Emerging Industries: Case from Electric Vehicles in China. Journal of Industrial Integration and Management, 5(1), 13-31. Advance online publication. doi:10.1142/S2424862219500143

Sun, J., Gao, J., Yang, B., \& Tan, R. (2008, September). Achieving disruptive innovation-forecasting potential technologies based upon technical system evolution by TRIZ. In 2008 4th IEEE International Conference on Management of Innovation and Technology (pp. 18-22). IEEE.

Viriyasitavat, W., Xu, L., Bi, Z., \& Sapsomboon, A. (2019). New Blockchain-Based Architecture for Service Interoperations in Internet of Things. IEEE Transactions on Computational Social Systems, 6(4), $739-748$. doi:10.1109/TCSS.2019.2924442

Vojak, B. A., \& Chambers, F. A. (2004). Roadmapping disruptive technical threats and opportunities in complex, technology-based subsystems: The SAILS methodology. Technological Forecasting and Social Change, 71(1-2), 121-139. doi:10.1016/S0040-1625(03)00047-7

Walsh, S. T. (2004). Roadmapping a disruptive technology: a case study: the emerging microsystems and topdown nanosystems industry. Technological Forecasting and Social Change, 71(1-2), 161-185. doi:10.1016/j. techfore.2003.10.003

Wang, S., Li, L., \& Jones, J. D. (2014). Systemic thinking on services science, management and engineering: Applications and challenges in services systems research. IEEE Systems Journal, 8(3), 803-820. doi:10.1109/ JSYST.2013.2260622

Wang, W., Niu, N., Alenazi, M., Savolainen, J., Niu, Z., Cheng, J., \& Xu, L. (2020). Complementarity in Requirements Tracing. IEEE Transactions on Cybernetics, 50(4), 1395-1404. doi:10.1109/TCYB.2018.2889830 PMID:30640642

Whitmore, A., Agarwal, A., \& Xu, L. (2015). The Internet of Things-A Survey of Topics and Trends. Information Systems Frontiers, 17(2), 261-274. doi:10.1007/s10796-014-9489-2

Wu, J., Li, L., \& Xu, L. (2014). A randomized pricing decision support system in electronic commerce. Decision Support Systems, 58, 43-52. doi:10.1016/j.dss.2013.01.015

Xiao, G., Guo, J., Xu, L., \& Gong, Z. (2014). User Interoperability with Heterogeneous IoT Devices through Transformation. IEEE Transactions on Industrial Informatics, 10(2), 1486-1496. doi:10.1109/TII.2014.2306772

Xu, B., Xu, L., Cai, H., Xie, C., Hu, J., \& Bu, F. (2014). Ubiquitous Data Accessing Method in IoT-based Information System for Emergency Medical Services. IEEE Transactions on Industrial Informatics, 10(2), 1578-1586. doi:10.1109/TII.2014.2306382

$\mathrm{Xu}$, L. (2000). The Contribution of Systems Science to Information Systems Research. Systems Research and Behavioral Science, 17(2), 105-116. doi:10.1002/(SICI)1099-1743(200003/04)17:2<105::AIDSRES287>3.0.CO;2-M

$\mathrm{Xu}$, L. (2011). Enterprise Systems: State-of-the-Art and Future Trends. IEEE Transactions on Industrial Informatics, 7(4), 630-640. doi:10.1109/TII.2011.2167156

$\mathrm{Xu}, \mathrm{L}$. (2016). Inaugural Issue Editorial. Journal of Industrial Information Integration, 1, 1-2. doi:10.1016/j. jii.2016.04.001

Xu, L., Cai, L., Zhao, S., \& Ge, B. (2016). Editorial: Inaugural Issue. Journal of Industrial Integration and Management, 1(1), 1601001. doi:10.1142/S2424862216010016

Xu, L., He, W., \& Li, S. (2014). Internet of Things in Industries: A Survey. IEEE Transactions on Industrial Informatics, 10(4), 2233-2248. doi:10.1109/TII.2014.2300753

Xu, L., \& Viriyasitavat, W. (2019). Application of Blockchain in Collaborative Internet of Things Services. IEEE Transactions on Computational Social Systems, 6(6), 1295-1305. doi:10.1109/TCSS.2019.2913165 
Xu, L., Xu, E., \& Li, L. (2018). Industry 4.0: State of the Art and Future Trends. International Journal of Production Research, 56(8), 2941-2962. doi:10.1080/00207543.2018.1444806

Xu, S., \& Liang, Z. (2016). The Technology foresight faced 2035 in the electronic information field. Journal of China Academy of Electronics and Information Technology, 11(4), 89-93.

Yang, P., \& Xu, L. (2018). The Internet of Things (IoT): Informatics methods for IoT-enabled health care. Journal of Biomedical Informatics, 87, 154-156. doi:10.1016/j.jbi.2018.10.006 PMID:30342221

Yin, Y., Xu, B., Cai, H., \& Yu, H. (2020). A novel temporal and spatial panorama stream processing engine on IoT applications. Journal of Industrial Information Integration, 18, 100143. doi:10.1016/j.jii.2020.100143

Zhang, C. (2019). Research on the Fluctuation and Factors of China TFP of IT Industry. Journal of Industrial Integration and Management, 4(4), 1950013. doi:10.1142/S2424862219500131

Zheng, X., Martin, P., Brohman, K., \& Xu, L. (2014). Cloud Service Negotiation in Internet of Things Environment: A Mixed Approach. IEEE Transactions on Industrial Informatics, 10(2), 1506-1515. doi:10.1109/ TII.2014.2305641

Weifeng Jia is an associate professor of the Economic and Management School in Xi'an University of Posts and Telecommunications, Xi'an, Shaanxi, P.R. China. His main teaching interests are in the areas of operation management and knowledge management. His current research focuses on innovation network and global information technology. Weifeng Jia is also a reviewer of National Natural Science Foundation of China. He is member of the China Technical Economics Association. He has also secured grants from the China National Science Foundation.

Yongping Xie is a professor of the Economic and Management School in Xidian University, Xi'an, Shaanxi, P.R. China. Now he is Department head of business management. His main teaching interests are in the areas of operation management and supply chain management. His current research focuses on innovation network and network governance, especially on the alliance leadership of core firm. Yongping Xie is also a reviewer of National Natural Science Foundation of China. He is member of the Chinese Institute of Business Administration. He has also secured grants from the China National Science Foundation.

Zhao Yanan is a Doctoral studentst of the School of Economics and Management in Xidian University, Xi'an, Shaanxi. Her main research interests are information systems and knowledge management.

Yao Ke is graduate student at the School of Economics and Management of Xi'an University of Posts and Telecommunications,Xi'an, Shaanxi, P.R. China.. Her main research interests are information systems and information management.

Hui Shi is an Assistant Professor of the Computer Information Systems Department at Cal Poly Pomona. She received a B.S. in Computer Science and Technology from Hefei University of Technology, China, a M.S. in Computer Application Technique from Hefei University of Technology, China, and a Ph.D. in Computer Science from Old Dominion University. Her research interests include Data Mining, Big Data, Social Media Analysis, Information Visualization, Semantic Web and Computer Supported Cooperative Work.

Dazhi Chong received his PHD in Information Technology from Old Dominion University, Norfolk, Va. As an assistant professor of California Lutheran University, his research covers a wide range of topics in the IT discipline, including Information Systems, Social Network Analysis, Computer Supported Cooperative Work, Data Mining, and Financial Analysis. 